\title{
Para pensar el conflicto, el cambio y algún aspecto del caos
}

Clivatge vuelve a hacer su aparición, pero esta vez con un conjunto de piezas sueltas y autónomas que, aunque no responden a un único tema central, invitan a la reflexión sobre las condiciones en las que se producen los cambios sociales, se impiden, o se promueven, a veces, en dirección opuesta a como cualquier baremo sensato de civilización y humanidad establecería. Con cada uno de los artículos, reseñas o estudios que presentamos, la revista trata de ofrecer, en esta ocasión, información y marcos de pensamiento y acción que pueden resultar de interés, e incluso novedosos, para sus lectores. Este número 6 compone una miscelánea de temas seleccionados por su valor intrínseco, pero también intencionadamente para abrir, lo más posible, a los lectores, usuarios y potenciales autores el abanico de perspectivas, de tonos de reflexión, de disciplinas de partida en los análisis, y de localizaciones en las que parar nuestra atención para investigar sobre el cambio y los conflictos sociales. Los editores de esta revista creemos que era obligado hacer este nuevo número 
con esta orientación, después de haber publicado en el extenso número anterior un tema tan especializado y monográfico como el que compusieron los análisis que se habían hecho del cambio social, político, cultural y económico esencialmente desde la geografía urbana. Aclarado este punto, pasamos, pues, a presentar ahora los elementos que componen este número.

El artículo titulado Alternative Currencies and Democratic Conflict: Some Reflections reflexiona y analiza cómo las denominadas "monedas alternativas", cuya atención, interés y número han aumentado en medio de nuestra Crisis contemporánea, se interconectan no de manera armoniosa con los estados nacionales y sus particulares desarrollos democráticos, porque rompen sus fronteras y señalan sus límites. Tales monedas, como apuntan los autores del artículo, abren un proceso nuevo en el estado actual de la globalización económico-financiera, en el que se pierde la perspectiva de la dirección y el control completo de la velocidad infinitamente acelerada que el uso de estas monedas puede imponer en los movimientos económicos. Con este artículo, sus autores nos invitan a pensar sobre esta cuestión de la mano de la información que nos suministran y con las evaluaciones que ellos mismos hacen, por momentos tan explícitas como esta que leemos en sus conclusiones: "...cryptocurrencies promote a kind of 'individual' 
democracy where economic agents can vote with their feet by choosing the composition of their cryptocurrency wallets without any institutional intervention. This political preference seems incompatible with maintaining high democratic standards, in line with the role of money regulation presented in our theoretical framework. Thus, in conclusion, it seems that the global application of cryptocurrencies would only reduce democracy by reinforcing globalization".

En Una Geografía del Poder: La Minería Transnacional en Perú y Argentina, el profesor Philippe Dautrey nos ofrece un panorama de injusticias sociales, acometidas sobre las poblaciones sin poder económico ni político, que son resultado banal -diría Hanna Arendtdel abuso de poder que ejercen los actores económicos transnacionales, en colaboración con gobiernos, cuando simplemente persiguen sus intereses crudos de conquistar imparablemente beneficios. Esencialmente, las poblaciones pierden la posibilidad de asegurar su subsistencia y su modo de vida completo en el tiempo de largo plazo, pierden el control de lo que en el artículo se denomina "la territorialidad", esto es, la conexión natural que cualquier sociedad desarrolla, o debe desarrollar, con su entorno, si es que quiere que la vida sea sostenible. Hay, en este trabajo, un tono de denuncia explícita de las confabulaciones que los Estados y los grupos económicos transnacionales realizan para 
despojar de la tierra, de los bienes, del trabajo, incluso del sentido, a las poblaciones que someten, en pos de alcanzar únicamente el interés sin límite del beneficio. Como se señala allí (y desde el marco del estudio que impone nuestra revista), el cambio social que las posiciones neoliberales promueven es siempre de signo negativo y éste se produce en medio de conflictos, aunque se busque de mil maneras que tales conflictos sean abortados o silenciados, y ahí es donde colaboran también, en este complot, los medios de información y comunicación. Nos satisface, pues, que nuestra revista, como medio de información (aunque desde la academia), sirva para dar eco a este tipo de trabajos en los que el peso de la denuncia puede ganar por momentos al detalle del análisis.

En el estudio comparativo entre España y Argentina que realiza Joaquim Juan Albalate, el objetivo es tratar de ver por qué en los momentos de máxima crisis hay contextos, como el español, que parecen no haber ampliado el uso de la huelga como instrumento de reivindicación de derechos laborales y sociales. La guía de la comparación con el caso argentino le sirve a este especialista de la Sociología del Trabajo para entender esta cuestión, o al menos para mostrarnos cuáles son algunas de las condiciones que rigen con valores diferentes en ambos países, y que hacen que paradójicamente las huelgas no se intensifiquen en contextos y 
circunstancias como el de la Crisis que de manera natural las reclaman. Cabe destacar de este trabajo, además del interés de la cuestión central que lo orienta, la síntesis equilibrada que nos ofrece de la teoría desarrollada sobre los motivos de la huelga, así como el buen conocimiento que el autor tiene de las particularidades del conflicto laboral español.

Sobre el trabajo de Gonçal Mayos, no hay mejor manera de presentarlo que recurrir a sus propias palabras: "La 'tesis de la secularización' coincidía con la metáfora de 'la muerte de Dios' en predecir la irremisible desaparición de la religión de la esfera política y pública de las sociedades modernas. Tres grandes tendencias se sumaban en ese proceso de larga duración histórica: reducir la religión al ámbito privado de la población, racionalizar los elementos teológicos restantes o bien sustituirlos por ideologías y 'grandes relatos' laicos. Sin embargo, a partir de los años de 1970 se manifiesta otra tendencia histórica que coincide con la metáfora de 'la venganza de Dios', que destaca el poderoso y conflictivo retorno de la religión a la esfera público-política. Analizamos el contexto, causas y consecuencias de ese cambio tan importante como inesperado". Después de esto, solo falta añadir el sentido que tiene la selección de este artículo para nuestra revista. 
El autor le ha dado un título a este artículo sugestivo, pero al mismo tiempo algo enigmático: De la «muerte de Dios» a la «revancha de Dios»: política, cultura, terrorismo... Sin embargo, pese a lo que pueda parecer, sobre lo que en él reflexiona no es sobre una cuestión teológica, sino que lo que hace es presentar desde la Filosofía la síntesis de un amplio proceso de cambio social en el que la religión como instancia de poder pierde su lugar, proceso que es reflexionado a posteriori, desde la Filosofía, como una conquista. Hecho esto, y sin abandonar a los filósofos, el autor se coloca en nuestro tiempo contemporáneo más cercano, a partir de la década de los setenta, para dar los trazos de otro proceso en el que las religiones pasan a ser el ropaje con el que se envuelven algunas de las instancias de poder actuales para justificar sus acciones, para activar conflictos, para cometer grandes atrocidades.

Lo que en el artículo esencialmente se reflexiona, sin perder la guía que brindan los autores desde la Filosofía, es que, sea como sea, con las formas de poder actual, el rostro y la esencia de la Modernidad parecieron otorgar a la Religión una posición de derrota (expresada en la metáfora de "la muerte de Dios"); aun así, ésta ha reaparecido en la escena actual con tintes de venganza.

La reflexión filosófica forma parte esencial del orden cultural que, junto con el orden político y tecnoeconómico, configura cualquier

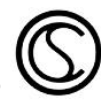


sociedad, tal y como nos explicó el sociólogo Daniel Bell, y en este sentido, el artículo de Mayos viene a corroborar lo que el mismo Bell diagnosticó en su balance sobre la evolución de las sociedades, esto es, que en el orden cultural las preguntas a las que las sociedades intentamos dar respuesta son siempre las mismas, lo que varía es la forma de respuesta concreta que se da en el tiempo exacto de la evolución social que consideremos. La muerte y la venganza de Dios creemos que son válidas como metáforas si con ellas lo que se quiere expresar es que ha cambiado el rostro del poder (el actual respecto del pasado), también que ha cambiado la forma en la que se expresan sus consecuencias, porque, como demuestra la historia, nunca ha sido derrotado. Y esta es la gran pregunta a la que probablemente seguiremos volviendo: ¿Por qué el ser humano no consigue articular formas de vida colectiva sin Poder y sin sus terribles consecuencias?, o lo que es lo mismo, ¿qué hay en la esencia humana que requiera del desarrollo de formas distintas de Poder?

Pero contra el panorama negativo que son las consecuencias del Poder, lo que sigue en la sección Testimonios viene a representar un ejemplo concreto de otro de los aspectos de lo humano, y que señala su contradicción. Porque lo que presentamos en esta sección es el denominado Proyecto B-MINCOME, un caso particular de acción con el que el ayuntamiento de Barcelona trata de paliar aspectos 
urgentes de atención por la desigualdad en la que viven un número importante de hogares de una zona de esta ciudad. Creemos que tenemos la obligación de difundir este tipo de experiencias, no solo para darlas a conocer por lo más valioso de lo humano que las orienta, sino para que se repliquen y se extiendan allí donde se pueda, y allí donde el poder —en este caso- político deje un resquicio.

El resto de elementos que componen este número se ubican en nuestra sección de Reseñas y Estudios, y en ella damos a conocer una serie de publicaciones que creemos que vale la pena que nuestros lectores conozcan, busquen y lean, porque cada una de ellas es una pieza de información valiosa sobre el estado del mundo y sirve para tratar de orientar mejor nuestra acción, individual y colectiva. Los mismos títulos de las reseñas, tal y como nos las han hecho llegar sus autores, sirven de guía para identificar los temas de interés que proponemos a nuestros lectores. Ahora solo anticipamos que uno de los temas urgentes que las reseñas apuntan es la triste experiencia de los Refugiados, y que otro, en forma de noticia editorial, es el Proceso de Paz en Colombia. 
No podemos dejar de mencionar en esta presentación algo sobre el contexto más cercano desde donde publicamos, que es Barcelona, $y$, por lo tanto, se halla en medio de lo que se denomina, en castellano, el proceso de independencia en Catalunya. Pero nos vamos a limitar a eso, a mencionarlo, para que desde cualquier otro lugar desde donde se lea nuestra revista se tenga en cuenta, porque a veces lo que ocurre fuera tiene, en ocasiones, efectos paradójicos: por un lado, la vida diaria de acción, movilización y debate nos lleva a no poder ver casi nada fuera de las fronteras de nuestros límites cotidianos y más próximos, hasta el punto de que el entorno se incrusta como un eje que no puedes abandonar, y por otro, el trabajo de editar y pensar nos obliga a saltar nuestras propias fronteras y nos vemos fuera de nuestras preocupaciones más cercanas, no sin un regusto de tristeza y cierto caos, sabiendo que todavía no estamos preparados para analizar lo que es, en nuestro caso, urgente y necesario.

\section{María Trinidad Bretones ${ }^{1}$}

1 Professora de la Universitat de Barcelona, Cap d'Estudis del Grau de Sociologia, y Directora de Clivatge 